\title{
Norepinephrine and Learning-Induced Plasticity in Infant Rat Olfactory System
}

\author{
Regina M. Sullivan, ${ }^{a}$ Donald A. Wilson, ${ }^{a}$ and Michael Leon \\ Department of Psychobiology, University of California, Irvine, California 92717
}

\begin{abstract}
Postnatal olfactory learning produces both a conditioned behavioral response and a modified olfactory bulb neural response to the learned odor. The present report describes the role of norepinephrine (NE) on both of these learned responses in neonatal rat pups. Pups received olfactory classical conditioning training from postnatal days (PN) 118. Training consisted of 18 trials with an intertrial interval of $24 \mathrm{hr}$. For the experimental group, a trial consisted of a pairing of unconditioned stimulus (UCS, stroking/tactile stimulation) and the conditioned stimulus (CS, odor). Control groups received either only the CS (Odor only) or only the UCS (Stroke only). Within each training condition, pups were injected with either the NE $\beta$-receptor agonist isoproterenol $(1,20$, or $4 \mathrm{mg} / \mathrm{kg})$, the NE $\beta$-receptor antagonist propranolol $(10,20,40 \mathrm{mg} / \mathrm{kg})$, or saline $30 \mathrm{~min}$ prior to training. On day 20, pups received one of the following tests: (1) behavioral conditioned responding, (2) injection with ${ }^{14} \mathrm{C}$-2-deoxyglucose (2-DG) and exposed to the CS odor, or (3) tested for olfactory bulb mitral/tufted cell single-unit responses to the CS odor. The results indicated that training with either: (1) Odor-Stroke-Saline, (2) Odor-Stroke-Isoproterenol-Propranolol, or (3) Odor only-Isoproterenol (2 $\mathrm{mg} / \mathrm{kg}$ ) was sufficient to produce a learned behavioral odor preference, enhanced uptake of ${ }^{14} \mathrm{C}-2-\mathrm{DG}$ in the odor-specific foci within the bulb, and a modified output signal from the bulb as measured by single-cell recordings of mitral/tufted cells. Moreover, propranolol injected prior to Odor-Stroke training blocked the acquisition of both the learned behavior and olfactory bulb responses. Thus, NE is sufficient and may be necessary for the acquisition of both learned olfactory behavior and olfactory bulb responses.
\end{abstract}

Early olfactory learning is critical for survival in infant rats. Pups must learn about odors for orientation to their mother (Johanson and Teicher, 1980; Johanson and Hall, 1982; Johanson et al., 1984; Sullivan et al., 1986a, b) and nipple attachment (Pedersen et al., 1982), as well as other behaviors (Leon et al., 1977; Brunjes and Alberts, 1979; Galef and Kaner,

\footnotetext{
Received Nov. 16, 1988; revised May 22, 1989; accepted June 7, 1989.

This research was supported by NICHD grant HD0681, NINCDS grant NS26100, and PEW Charitable Trusts to R.M.S. and NS grant 21484 from NINCDS to M.L., who holds a Research Scientist Development Award MH 00371 from NIMH, and NSF grant BNS8606786 to D.A.W. and M.L.

Correspondence should be addressed to Regina M. Sullivan, Developmental Psychobiology Laboratory, Department of Psychology, University of Oklahoma, Norman, OK 73019.

a Present address: Developmental Psychobiology Laboratory, Department of Psychology, University of Oklatıoma, Norman, OK 73019.

Copyright (C) 1989 Society for Neuroscience $0270-6474 / 89 / 113998-09 \$ 02.00 / 0$
}

1980; Alberts and May, 1984). One manner in which pups learn about odors is through pairing that odor with tactile stimulation (Pedersen et al., 1982; Sullivan et al., 1986a, b), which is normally experienced during contact with the dam. This early olfactory learning appears to conform to a classical conditioning paradigm (Sullivan and Hall, 1988).

Previous research from our laboratory has shown that the olfactory bulb is modified as a result of this early olfactory learning. Upon presentation of a conditioned odor, pups exhibit enhanced focal glomerular layer ${ }^{14} \mathrm{C}$-2-deoxyglucose (2-DG) uptake (Sullivan and Leon, 1986, 1987), altered mitral/tufted cell responding (Wilson et al., 1987; Wilson and Leon, 1988a), and modified glomerular morphology (Woo et al., 1987) within odorspecific regions of the bulb. The altered olfactory bulb response does not occur following experience with only the odor (Sullivan and Leon, 1986; Wilson et al., 1987), is specific to the conditioned odor (Wilson et al., 1985, 1987; Coopersmith et al., 1986), and lasts into adulthood (Coopersmith and Leon, 1986). Furthermore, the neurobehavioral response is acquired rapidly (Sullivan and Leon, 1987) during a sensitive period within the first week of life (Woo and Leon, 1988).

Importantly, these neurobehavioral changes do not occur following exposure to the odor in the absence of concurrent reinforcing (Sullivan and Hall, 1988) stimulation (Sullivan and Leon, 1986; Wilson et al., 1987; Sullivan et al., 1989). The present work is an attempt to define pharmacologically the substrates of odor-reinforcer association which may be necessary and/or sufficient to produce functional and structural plasticity in the olfactory bulb. Specifically, this report describes the role of norepinephrine (NE) in the acquisition of neurobehavioral responses to odors following postnatal olfactory conditioning.

Many lines of research point to NE as being critical for perinatal neurobehavioral plasticity. For example, deprivation-induced plasticity of visual cortical neuron receptive fields is dependent on the presence of NE during the deprivation period (Kasamatsu and Pettigrew, 1979; Bear and Singer, 1986). In the olfactory system, manipulation of NE alters pup learning about odors (Morasco et al., 1979; Pedersen et al., 1982; CornwellJones and Bollers, 1983). In mature animals, NE modulates main olfactory bulb responses to biologically significant and learned odors (Gervais and Pager, 1983; Rosser and Keverne, 1985; Gray et al., 1986; Gervais et al., 1988). Furthermore, the tactile stimulation used as a reinforcer in early olfactory learning activates noradrenergic locus coeruleus neurons in rats as young as $1 \mathrm{~d}$ after birth (Nakamura et al., 1987), and over $40 \%$ of locus coeruleus neurons project to the olfactory bulb (Shipley et al., 1985). This noradrenergic input is present (McLean and Shipley, 1987) and functional (Wilson and Leon, 1988b) in the olfactory bulb as early as the end of the first postnatal week. Thus, the 
noradrenergic system has a significant role in olfactory functioning and is critically situated to have an important influence on conditioning-induced plasticity in the newborn.

The present work, however, is one of the first attempts to assess the role of NE in both the behavioral and neural changes associated with learning in the neonate. Thus, the experimental situation was designed to closely approximate the natural distribution of NE during early learning, rather than focus entirely on the olfactory system. Toward that end, systemic injections, rather than intrabulbar injections, were used to manipulate NE both peripherally and centrally. Indeed, the infant rat is an ideal subject for the manipulation since the drugs used here pass the immature blood-brain barrier (Mirkin, 1970). Systemic injections also have the benefit of requiring no surgical intervention, and thus, limit the amount of stress and extraneous stimulation the pups receive, which are particularly important variables in pup lcarning. The results suggest that NE is sufficient and possibly necessary for the acquisition of both conditioned behavioral and olfactory bulb neural responses to learned odors.

\section{Materials and Methods}

Subjects. The subjects were male and female preweanling rat pups from litters born of Wistar rats (offspring of Hilltop Lab Animals, Scottsdale, PA) in the animal care facilitics at either the University of California or the University of Oklahoma. Dams were housed in rectangular polypropylene cages $(34 \times 29 \times 17 \mathrm{~cm})$ lined with wood chips in a temperature $\left(23^{\circ} \mathrm{C}\right)$ and light $(0800-2000 \mathrm{hr})$ controlled room. Ad lib food and water were available at all times. Mothers were fed a special diet (Teklad Diet TD69446, Madison, WI) that suppressed their dominant odor to minimize extraneous odor experience by pups (Leon, 1974). Births were checked at 0800 and $1700 \mathrm{hr}$. The day of birth was considered to be postnatal (PN) day 0 .

Litters were culled to 9 pups on PN 1. There were 3 drug conditions (noradrenergic agonist, antagonist, and saline) and 3 postconditioning tests (odor-preference, ${ }^{14} \mathrm{C}$-2-DG autoradiography, and single-unit recording), thus no more than 1 pup from a given litter was used in an experimental condition. Pups were trained from PN 1-18, and tested on PN 20, as described below.

Drug administration. On PN 1-18, 30 min prior to the daily odor conditioning, pups were injected with either (1) NE $\beta$-receptor agonist (-)isoproterenol $(1,2$, or $4 \mathrm{mg} / \mathrm{kg}$ dose, s.c.), (2) the NE $\beta$-receptor antagonist DL-propranolol $(10,20$, or $40 \mathrm{mg} / \mathrm{kg}$ dose, s.c.), (3) both isoproterenol $(2 \mathrm{mg} / \mathrm{kg}$ ) and propranolol $(20 \mathrm{mg} / \mathrm{kg}$ ), or (4) saline (volume of $5 \mathrm{cc} / \mathrm{kg}$ ). Pups were returned to the dam following injection and remained with her until training.

Odor conditioning. Odor conditioning consisted of 18,10 min training sessions with an intertrial interval of $24 \mathrm{hr}$. On PN 1, pups were assigned to one of the following training groups: (1) Odor-Stroke-pups were exposed to peppermint odor while being vigorously stroked with a sable hair brush; (2) Odor only; or (3) Stroke only. The tactile stimulation produced by stroking was used to mimic maternal stimulation (Barnett and Walker, 1974; Evoniuk et al., 1978; Kuhn et al., 1978; Hofer, 1987) and has reinforcing properties to infant rats (Sullivan et al., 1986a, b; Sullivan and Hall, 1988). The odor was peppermint extract (Schilling, Baltimore, MD) presented in a 1:10 dilution at 2 liters/min with a flowdilution olfactometer. Pups remained with the dam until 10 min prior to training, at which time they were placed in individual $1000 \mathrm{ml}$ glass cylinders. Following a $10 \mathrm{~min}$ adaptation period in which pups recovered from experimental handling, training began. Following training, pups were returned to the dam for $24 \mathrm{hr}$.

Behavioral observations during training. In order to assess possible general behavioral effects of isoproterenol and propranolol, pup behavior was observed during training at PN 5, 10, and 15. A hehavioral rating scale was used in which the level of behavioral activity is rated (Hall, 1979); 0, not active; 1, movement of 1 body part (i.e., head rearing); 2 , movement of 2 body parts (i.e., treading); 3 , movement of 3 body parts (i.e., pivoting); 4 , movement of 4 body parts (i.e., locomotion). Pups were observed every $1 \mathrm{~min}$ for $5 \mathrm{sec}$.

Behavioral testing. On PN 20, $48 \mathrm{hr}$ after the last training session, pups were given a behavioral odor preference test. The test consisted of a 2-odor choice between the conditioned pcppcrmint odor and a familiar pine odor. The test apparatus consisted of an $(40 \times 21 \times 15$ $\mathrm{cm})$ opaque Plexiglas box with a small grid wire mesh $(1 \times 1 \mathrm{~cm})$ floor divided in half by a 2-cm-wide "neutral zone" which ran the length of the box. Two trays $(20 \times 30 \times 5 \mathrm{~cm})$, each containing $500 \mathrm{ml}$ of shavings was placed beneath each half of the wire mesh floor. One tray contained a peppermint odor (pine shavings scented with $1 \mathrm{ml}$ of peppermint extract), and the other contained a familiar pine odor (clean pine shavings on which the pup is raised). A 1 min trial test began by placing a pup in the neutral zone. When the pup's head and forepaws crossed from the neutral zone to either the CS peppermint odor or the familiar pine odor, the experimenter started recording the time. At the end of the test, the total time the pup spent over each of the 2 odors was recorded by using a microcomputer program. Pups were tested for 5 trials, and between cach 1 min trial, the pup was taken out of the test box. The direction in which pups were placed into the box was counterbalanced across trials.

${ }^{14} C-2-D G$ autoradiography. In order to limit the number of animals used, only pups trained at the maximally effective doses of isoproterenol and propranolol were used for 2-DG autoradiography and single-unit recording (see below). For the odor/2-DG test on PN20, pups were injected with ${ }^{14} \mathrm{C}-2-\mathrm{DG}(20 \mu \mathrm{Ci} / 100 \mathrm{gm})$ immediately prior to odor delivery and placed in a glass test canister $(29 \times 11 \mathrm{~cm})$ covered with an air-tight plastic lid. Respiration was monitored by a pressure-sensitive transducer connected to a Columbus Instruments respiration monitor.

Following the 45 min odor delivery (Kelly and McCullough, 1981), pups were rapidly decapitated and their brains immediately frozen $\left(45^{\circ} \mathrm{C}\right.$ ) and storcd at $70^{\circ} \mathrm{C}$, and coronal scetions werc cut at $20 \mu \mathrm{m}$ at $-18^{\circ} \mathrm{C}$. Brain sections and ${ }^{14} \mathrm{C}-2-\mathrm{DG}$ standards were then exposed to Kodak SB5 X-ray film for $10 \mathrm{~d}$. The resulting autoradiographs were analyzed with the aid of a computer-based digital image processor (Spatial Data) that allowed pseudocolor imaging and 2-dimensional quantitative optical densitometry (Gallistel et al., 1982). To quantify 2-DG uptake, the computer constructed a calibration curve that related the gray value of ${ }^{14} \mathrm{C}$ standards that were exposed with the brain sections to that of the previously determined ${ }^{14} \mathrm{C}$ tissue equivalent. The computer then linearized this function, thereby allowing the gray values of the autoradiographs to be translated into ${ }^{14} \mathrm{C}$ levels, and hence 2-DG uptake by the tissue.

The autoradiographs were then optically scanned for the odor-specific 2-DG spatial pattern and sections in this area were analyzed. The odorspecific pattern of focal 2-DG uptake (Stcwart et al., 1979; Jourdan ct al., 1980; Greer et al., 1981; Astic and Saucier, 1982, 1986; Sharp et al., 1983; Coopersmith and Leon, 1984) is easily identified and limited to the glomerular layer (Sharp et al., 1975). In each section, 5 readings (each 9 pixels) were taken within the peppermint-responsive areas of the glomerular layer, which are $1.5-2.2 \mathrm{~mm}$ from the rostral pole of the olfactory bulb. Five readings were also taken in the regions of the glomerular layer that was not associated with a 2-DG focus. Five additional readings were taken in the periventricular core of the olfactory bulb. A ratio of glomerular-to-periventricular core 2-DG uptake was then calculated. The periventricular core was chosen as a baseline measure of 2-DG uptake because it has consistently low levels of 2-DG uptake in response to odor presentations (Jourdan et al., 1980). Thus, a ratio of average 2-DG uptake in the glomerular region to that of the periventricular core enables one to produce relative uptake measurements within the same section. This procedure eliminates interpretation problems due to minute differences in section thickness and background activity when analyzing the autoradiographs.

Single-unit recording. Pups used for single-unit recording on PN20 were anesthetized with urethane $(1.5 \mathrm{gm} / \mathrm{kg})$ and mounted in a stereotaxic apparatus. Their body temperature was maintained with a thermostatically controlled heating pad at $35^{\circ} \mathrm{C}$. Single-unit responses were recorded in the olfactory bulb with a glass microelectrode filled with 2 M NaCl. Single-unit recordings were made from mitral/tufted cells along the lateral aspect of the olfactory bulb, $1.5-2.2 \mathrm{~mm}$ from the rostral pole of the bulb, in the area of glomerular layer focal 2-DG uptake to peppermint (Wilson and Leon, 1988a). A bipolar stimulating electrode was placed in the lateral olfactory tract (LOT) to help identify mitral/ tufted cells. Mitral/tufted cells were identified by LOT-evoked response morphology and by the ability to activate such neurons antidromically from the LOT. Animals respired normally.

Odors were delivered to the external nares through glass tubing. Odor quality and quantity were matched to that used during training (pep- 

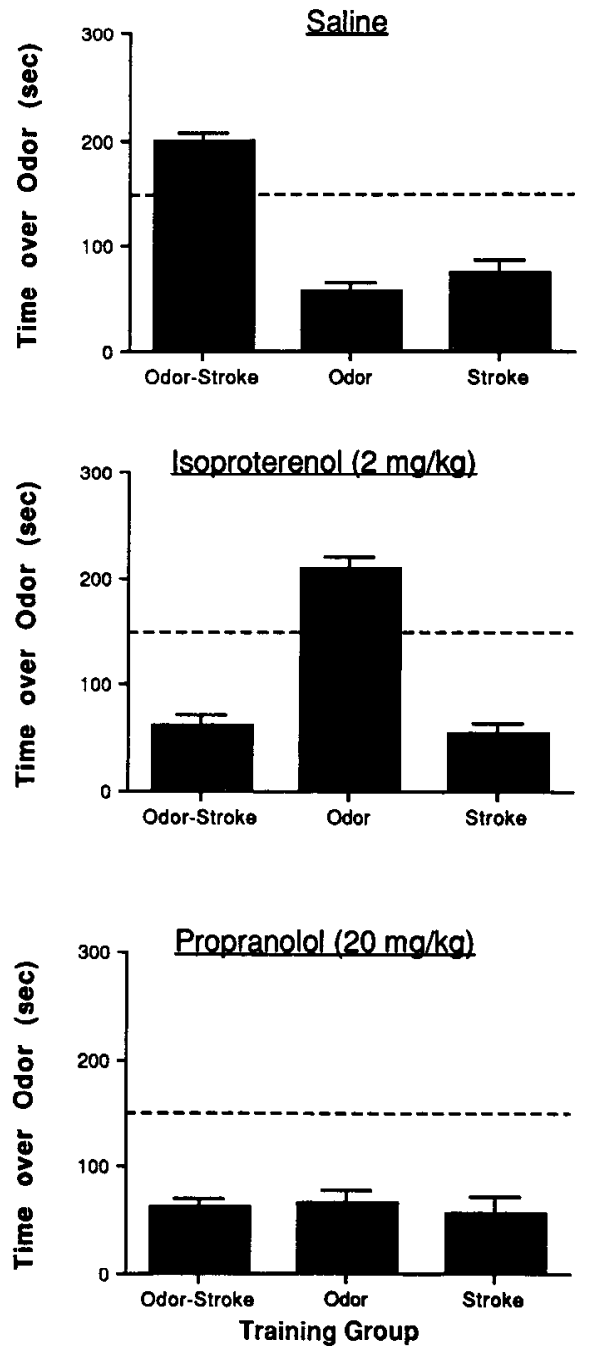

Figure 1. Mean time $( \pm \mathrm{SE})$ spent over pepperment odor $\mathrm{CS}$ in the 2 -odor choice test. Pups were previously trained in the Odor-Stroke, Odor only, and Stroke only conditioning groups and injected with saline, isoproterenol, or propranolol during training. Pups were not given any drug during testing. Only Odor-Stroke-Saline and Odor-Isoproterenol demonstrated a behavioral preference for the learned odor.

permint odor at a 1:10 dilution of saturated peppermint vapor, 2 liters/ min flow rate). Stimulus duration was $4 \mathrm{sec}$ with at least $60 \mathrm{sec}$ between stimuli. Responses were categorized as excitatory, suppressive, or no response according to specific criteria previously described (Wilson et al., 1987; Wilson and Leon, 1988a). Briefly, interspike interval during the odor stimulus was compared with mean interspike interval during the $10 \mathrm{sec}$ pre-odor baseline. A decrease in interspike interval (increase in firing rate) was classified as an excitatory response if the mean and standard errors of baseline and stimulus were nonoverlapping. Similarly, an increase in mean interspike interval (nonoverlapping standard errors) was classified as a suppressive response. An example of the response analysis is shown in Figure 4. To obtain a measure of the balance of excitation and suppression in response to the conditioned stimulus, an excitation ratio was then calculated for all training groups as the (percent cells excited/total percent responsive). An excitation ratio of greater than 0.50 signifies that more excitatory than suppressive responses were observed, while a ratio of less than 0.50 signifies the opposite. Excitation ratios were compared between conditioning and drug groups with $\chi^{2}$ tests.

\section{Results}

During the behavioral and neural testing, pups were not under the direct influence of noradrenergic drugs, as they were not injected with propranolol or isoproterenol for $48 \mathrm{hr}$ prior to testing. These drugs are both short-acting and should have cleared the pups' systems by the time of the test (Goodman and Gilman, 1985; Wilson and Leon, 1988b).

\section{Behavioral observations of pups during training}

Pup behavior was observed in the Odor-Stroke and Odor only groups during training to assess the general effects of isoproterenol and propranolol on pups, with particular attention paid to the induction of hyper- or hypoactivity ( $n=5 /$ drug-training group). These drugs did not have any significant effects on the general behavior of pups at any age. Pups in the Odor-Stroke groups were being stimulated during the behavioral observations, and there were no significant drug effects on pup responsiveness to stimulation. Pups in the Odor only group were not stimulated during the behavioral observations, and there were no significant drug effects on pups in a nonstimulated state. Weight gain, as well as the day of eye opening were also noted, but no significant training/drug group differences were observed. Similar drug doses have been used in other studies on rat pups in which no adverse effects of the drugs on behavior were noted (Caza, 1984). Thus, the failure to note any drug effects on the general behavioral competence of pups suggests that the drug effects presented below may be specific to the acquisition of the conditioned responses.

\section{Behavioral odor-preference test}

As shown in Figure 1, pairing an odor with either stroking (and saline) or with isoproterenol $(2 \mathrm{mg} / \mathrm{kg}$ ) resulted in a learned behavioral preference for that odor. Learning was blocked by a pretraining injection of propanolol $(20 \mathrm{mg} / \mathrm{kg})$. Odor-StrokePropranolol pups did not exhibit a subsequent odor preference ( $n=7$ pups/drug-training group, $3 \times 3$ ANOVA, $F$ (training condition $\times$ drug) $=52.6, p<0.01$ : Post hoc tests revealed that the Odor-Stroke-Saline and the Odor-Isoproterenol groups were each significantly different from each of the remaining groups, with at least $p<0.05$ ). The effects of isoproterenol and propranolol appeared to be specific to the acquisition of the learned behavior since odor-naive pups receiving isoproterenol or propranolol performed similarly to saline pups in the odor-preference test.

Interestingly, pairing an odor with both stroking and isoproterenol did not produce an odor preference. However, if pups were given both the NE agonist, isoproterenol and the NE antagonist propranolol prior to Odor-Stroke training, pups learned ( $n=8 \mathrm{pups} /$ group; mean number of seconds spent over the peppermint odor for the Odor-Stroke-Isoproterenol-Propranolol group and the Odor-Isoproterenol-Propranolol group are, respectively, $171.5 \pm 14.0$ and $75.4 \pm 6.0 \mathrm{sec} ; t=7.91, p<$ 0.01 ). Additionally, pups that received both the NE agonist and antagonist prior to Odor only training did not exhibit an odor preference (see Discussion).

In order to more closely examine the role of isoproterenol and propranolol on behavioral odor-preference learning, additional animals ( $n=7 \mathrm{pups} /$ drug-training group) were trained to determine the dose-response relationship of these drugs. OdorStroke and Odor only conditioning groups were trained with either isoproterenol $(0,1,2$, or $4 \mathrm{mg} / \mathrm{kg})$ or propranolol $(0,10$, 20 , or $40 \mathrm{mg} / \mathrm{kg}$ ). Only a single $0 \mathrm{mg} / \mathrm{kg}$ dose group was trained in Odor-Stroke and Odor only, for a total of 7 drug conditions/ training group.

As shown in Figure 2, propranolol and isoproterenol had 
dose-dependent effects on learning $[2 \times 7$ ANOVA; $F$ (training $\times$ drug) $=14.05, p<0.01]$. Propranolol had straightforward effects on early learning. Pairing Odor only training with propranolol did not produce an odor preference at any propranolol dose. In Odor-Stroke pups, propranolol blocked odor-preference learning in a dose-dependent fashion. For example, while learning was completely blocked by 20 and $40 \mathrm{mg} / \mathrm{kg}$ propranolol compared with saline, the effect was intermediate at $10 \mathrm{mg} /$ $\mathrm{kg}$ (Fig. 2B). The effects of isoproterenol, however, were more complex. Pairing an odor with isoproterenol produced an inverted-U dose-response curve. Odor-Isoproterenol training at moderate doses $(2 \mathrm{mg} / \mathrm{kg})$ resulted in a learned odor preference. No learned odor preference was expressed after training with either low $(1 \mathrm{mg} / \mathrm{kg})$ or high $(4 \mathrm{mg} / \mathrm{kg})$ isoproterenol doses. Similarly, the odor preference produced by Odor-Stroke training was reduced by isoproterenol in a dose-dependent fashion, with the effect of $1 \mathrm{mg} / \mathrm{kg}$ isoproterenol intermediate between 0 and $2 \mathrm{mg} / \mathrm{kg}$ (Fig. $2 A$ ).

In summary, the results of the behavioral tests indicate that both Odor-Stroke and Odor-Isoproterenol pairings were sufficient to produce an odor preference, provided the isoproterenol was in a moderate dosage. High doses of isoproterenol or pairing isoproterenol with stroking reduced the learned odor preference. Moreover, the acquisition of a conditioned odor preference was blocked by propranolol. The remaining procedures, therefore, were performed only with those drug dosages that were effective in producing or preventing acquisition of a behavioral odor preference (isoproterenol, $2 \mathrm{mg} / \mathrm{kg}$; propranolol, $20 \mathrm{mg} / \mathrm{kg}$ ).

\section{Glomerular layer focal 2-DG uptake}

Results of the 2-DG autoradiography indicated that both OdorStroke and Odor-Isoproterenol training were sufficient to produce a subsequent modified olfactory bulb response to the conditioned odor. As shown in Figure 3, pups that learned an odor preference exhibited statistically more 2-DG uptake in the odorspecific foci in the glomerular layer than pups in groups that did not learn [ $n=5 \mathrm{pups} /$ drug training group; $3 \times 3$ ANOVA; $F$ (training $\times$ drug) $=10.39, p<0.01$; post hoc tests revealed that the Odor-Stroke-Saline and Odor only-Isoproterenol groups each significantly differed from each of the remaining training/ drug groups with at least $p<0.05$ ]. No changes were observed in the spatial distribution of focal 2-DG uptake across groups, only in the density of uptake within the spatial pattern. Moreover, training conditions which blocked the acquisition of an odor preference blocked the acquisition of the enhanced olfactory bulb 2-DG response (Odor-Stroke-Isoproterenol and OdorStroke-Propranolol training). These results do not appear to be due to nonspecific drug action, since Odor-Propranolol, OdorSaline, and none of the no-odor/drug training groups exhibited an enhanced olfactory bulb response. These results are consistent with the behavioral results.

The enhanced focal 2-DG uptake was not associated with a modified respiratory response to the CS. No difference between the treatment groups was detected in total number of respirations or in the respiration frequency distribution during the 2-DG test. These data are consistent with our previous work demonstrating that the enhanced focal 2-DG uptake is not dependent on modified respiratory responses (Sullivan et al., 1988).

\section{Mitral/tufted cell response}

The effects of pharmacological treatments on modified mitral/ tufted cell single-unit responses were in complete agreement

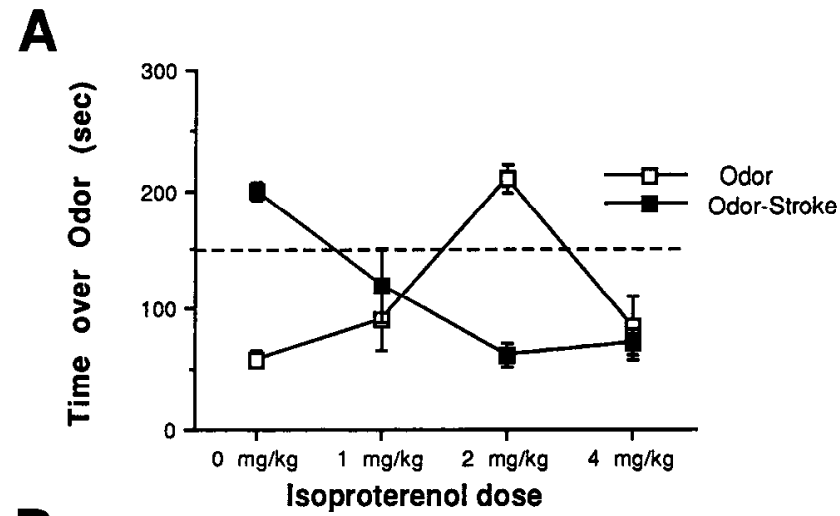

E

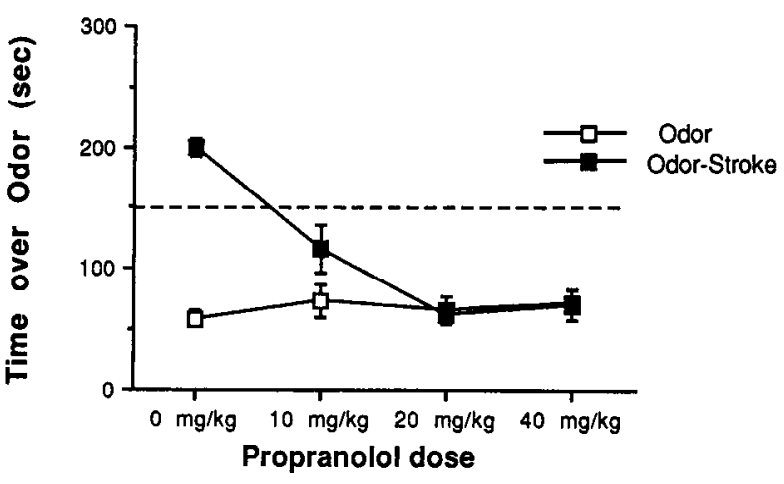

Figure 2. Mean time $( \pm \mathrm{SE})$ spent over peppermint odor CS during testing for pups previously treated with isoproterenol or propranolol during training in the Odor-Stroke and Odor only training conditions. $A$, Isoproterenol-Inverted U-shaped performance curve for Odor only and Odor-Stroke pups for each of the isoproterenol doses. $B$, Propanolol-Performance of Odor only and Odor-Stroke pups for each of the propranolol doses.

with the behavior and 2-DG results. A total of 211 identified mitral/tufted cells, recorded near the regions of focal glomerular layer 2-DG uptake to peppermint, were used in the analysis, with at least 20 cells from at least 4 pups in each group. Figure 4 diagrams the procedures for response analysis as described above in Materials and Methods.

The percentage of cells responding to the conditioned odor (excited or suppressed) did not differ between training groups or drug condition, ranging from $27.1 \%$ in Odor only to $32.2 \%$ in Stroke only pups (Odor-Stroke $=28.3 \%$ ). Antidromic spike latency and baseline spontaneous activity also did not differ between groups. However, as shown in Figure 5, of those cells that did respond to the conditioned odor, mitral/tufted cells in Odor-Stroke-Saline and Odor-Isoproterenol pups demonstrated more suppressive than excitatory responses to the learned odor (excitation ratio $<0.5$ ). Cells in all other groups showed the reverse-more excitation than suppression [Isoproterenol vs Saline, 2 (drug) $\times 3$ (training) $\chi^{2}=16.77, p<0.01$ ]. Thus, as demonstrated with both the behavioral and 2-DG responses, the effects of stroking could be mimicked by direct activation of the NE system with isoproterenol.

Furthermore, the effects of Odor-Stroke pairings on mitral/ tufted cell response patterns could be blocked by the NE-antagonist propranolol (Propranolol vs. Saline, $2 \times 3 \chi^{2}=7.23$, $p<0.05$ ). The combination of the odor with both stroking and isoproterenol also reduced the effects of Odor-Stroke pairings alone, as for the behavior and 2-DG responses (Fig. 5). 

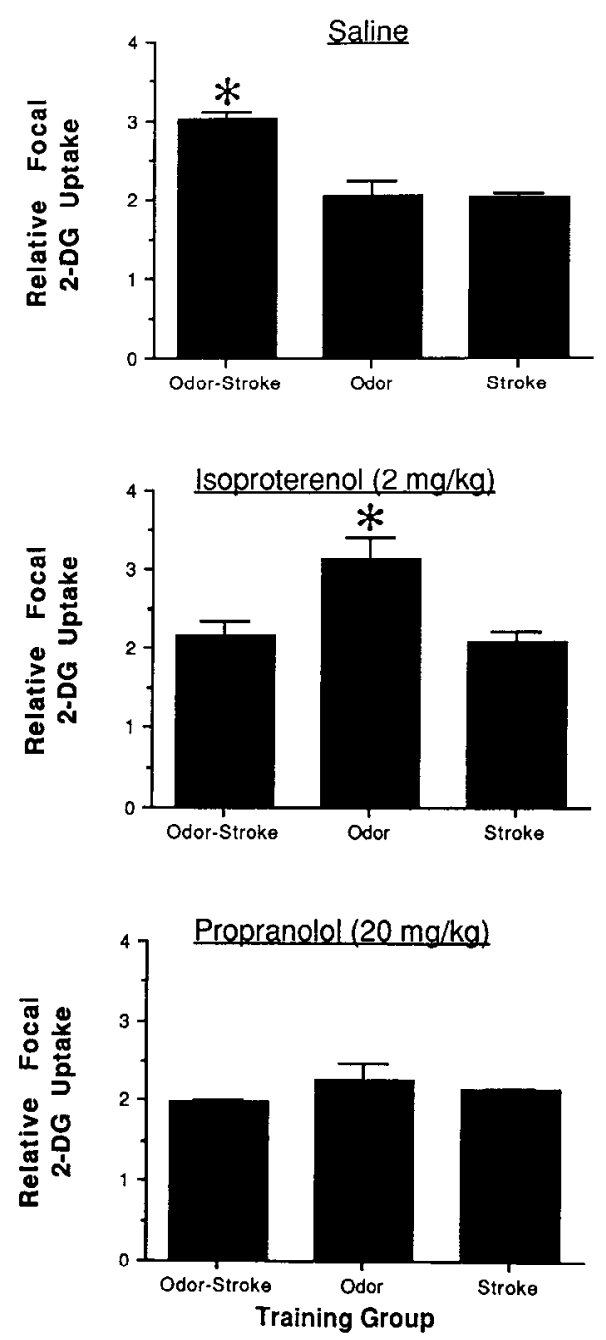

Figure 3. Mean relative 2 -DG uptake $( \pm \mathrm{SE})$ in the spatially odorspecific focal areas of the olfactory bulb during test exposure to peppermint odor. Pups had previously been trained in either the OdorStroke, Odor only, or Stroke only conditioning groups and injected with either saline, isoproterenol, or propranolol. Only Odor-Stroke-Saline and Odor-Isoproterenol demonstrated enhanced focal 2-DG uptake to the learned odor.

\section{Discussion}

$\mathrm{NE}$ appears to be sufficient and perhaps necessary for the acquisition of both the conditioned behavioral and olfactory bulb neural changes which pups acquire as a result of olfactory classical conditioning. Provided moderate dosages are used, isoproterenol can mimic the effects of stroking and propranolol can block the reinforcing properties of tactile stimulation. Indeed, the ability of both Odor-Stroke pairings and Odor-Isoproterenol pairings to result in an odor preference may be due to both stroking and isoproterenol activating NE receptors. Isoproterenol is an exogenous source of $\mathrm{NE}$ which acts upon $\mathrm{NE}$ $\beta$-receptors to mimic the action of NE. Stroking may evoke a rise in endogenous NE, since stroking activates locus coeruleus neurons in infant rats (Nakamura et al., 1987).

The blockade of early learning by propranolol is believed to be specific to the conditioned response, as opposed to a general decrement in behavioral competence, for several reasons. First, propranolol was present only during training; sufficient time was

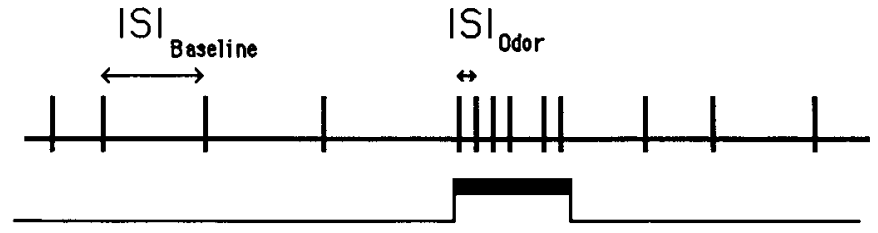

Figure 4. Example of analysis of mitral/tufted cell single-unit spike trains. The mean and SE of interspike intervals were determined for the $10 \mathrm{sec}$ pre-odor baseline and the $4 \mathrm{sec}$ odor stimulus. A decrease in interspike interval (increased firing rate) during the odor was classified as an excitatory response if the SEs, were nonoverlapping with the baseline SE. An increase in mean interspike interval (decreased firing rate) was classified as a suppressive response, given nonoverlapping SE.

given for elimination of the drug before testing began. Second, even during training, no significant effects of propranolol were observed on general behavioral activity levels. Third, when the effects of the agonist were blocked by simultaneous presentation of the antagonist, Odor-Stroke pups learned normally. Finally, propranolol-trained pups demonstrated the same preference for the control odor (clean pine wood chips) as did saline-trained control pups. These data also suggest that propranolol did not produce anosmia or alter olfactory sensitivity. In fact, it has recently been reported that depletion of olfactory bulb NE with 6-OHDA does not affect olfactory detection thresholds in mature rats (Doty et al., 1988). Thus, these results suggest that propranolol blocks the acquisition of a conditioned odor preference and associated neural responses.

Pairing an odor with either a high dose of isoproterenol (4 $\mathrm{mg} / \mathrm{kg}$ ) or with both stroking and isoproterenol (2 or $4 \mathrm{mg} / \mathrm{kg}$ ) blocked the acquisition of the modified neurobehavioral responses to that odor. These results are similar to a previous study which paired amphetamine and stroking with an odor (Pedersen et al., 1982) and to a study using 2 behavioral reinforcers when drugs were not utilized (Do et al., 1988). This inverted U-shaped dose-response curve is common for pharmacological modulators of learning (McGaugh, 1983; Martinez, 1986) and the exact mechanism is unclear. It has been hypothesized that presentation of 2 reinforcers, each of which independently produce learning, or presentation of a single reinforcer at a high dose can "overstimulate" pups, and result in poor learning. The results presented here suggest that NE may underlie the "overstimulation" hypothesis. First, exogenous sources of $\mathrm{NE}$ are dose dependent in their effect on acquisition, with moderate doses producing acquisition and high doses blocking acquisition. Second, exogenous and putative endogenous sources of NE seem to be additive, such that, similarly to a high dose of NE, acquisition is blocked if a moderate dose of NE is combined with stroking. Third, stroking and the exogenous source of NE, isoproterenol, appear to have similar pharmacological effects, since the antagonist propranolol is capable of blocking both. That is, the Odor-Stroke-Propranolol group did not learn (propranolol blocked endogenous NE), the Odor-Stroke-Isoproterenol-Propranolol group did learn (propranolol blocked either endogenous or exogenous NE), and the Odor-Isoproterenol-Propranolol group did not learn (propranolol blocked the exogenous $\mathrm{NE}$ ). The ability of propranolol to block the learning which normally occurs with Odor-Stroke pairings cannot be explained by "overstimulation," however, since propranolol (all dosages) and Odor pairings never resulted in learning. Furthermore, the ability of an NE receptor antagonist to block this olfactory learn- 
ing is not limited to propranolol, since the NE receptor antagonist timolol is also capable of blocking preweanling olfactory learning in a slightly different conditioning paradigm (R. M. Sullivan, J. L. McGaugh, and M. Leon, unpublished observations).

\section{$N E$ and neurobehavioral plasticity}

In the present studies, the NE system was manipulated by systemic injections. Thus, the noradrenergic modulation of olfactory bulb responses to learned odors may have been due to direct NE action within the bulb during training or may have been indirect via NE activation of another system during training. 'T he role of other neurotransmitter systems in early learning, therefore, should be examined. Furthermore, it should not be assumcd that ncurobchavioral olfactory learning occurs entirely within the olfactory bulb. Specifically, it is likely that olfactory bulb NE is necessary and sufficient for the olfactory bulb neural changes noted here. These changes presumably represent preliminary coding of learned olfactory information. However, olfactory bulb NE may be necessary but not sufficient to produce the learning-induced behavioral changes. Indeed, it is possible that the behavioral changes rely on a myriad of neural changes occurring throughout the brain, with the olfactory bulb representing only one of these areas. Thus, disruption of olfactory bulb NE with propranolol during conditioning may disrupt the acquisition of a learned behavioral response due to a disruption of the normal change of neural events which occur during learning. On the other hand, pairing an odor with olfactory bulb NE may fail to produce a learned behavioral response since only one of the neural events associated with reinforcement was mimicked. This is currently being tested.

With this note of caution in mind, however, there is extensive evidence that olfactory bulb function and olfactory behaviors are directly modulated by NE (see Gervais et al., 1988, for a review). While the olfactory bulb of the rat has no intrinsic NE neurons, the locus coeruleus projects over $40 \%$ of its neurons directly into the olfactory bulb (Shipley et al., 1985). This large $\mathrm{NE}$ input controls olfactory bulb excitability presumably via synaptic action on inhibitory granule cells (Jahr and Nicoll, 1982; Perez et al., 1987; Wilson and Leon, 1988b). Furthermore, NE (Brunjes et al., 1985) and NE-containing fibers (McLean and Shipley, 1987) are present and appear to be functional (Wilson and Leon, 1988b) in the rat olfactory bulb very early in postnatal development. Olfactory bulb NE is critical for acquisition of olfactory bulb neural changes associated with the acquisition of conditioned response in the adult rat and rabbit (Gervais and Pager, 1983; Royet et al., 1983; Gray et al., 1986), for mother-infant olfactory bonding in sheep (Pissonier et al., 1985) and for olfactory recognition of mates in mice (Keverne and de la Riva, 1982; Rosser and Keverne, 1985). Importantly, both the behavioral and olfactory bulb neural responses to these odors can be disrupted even when the blockade or destruction of NE is limited to the olfactory bulb (Keverne and de la Riva, 1982; Royct ct al., 1983; Pissonicr ct al., 1985; Rosser and Keverne, 1985; Gray et al., 1986).

The locus coeruleus projection to the olfactory bulb terminates fairly uniformly throughout the bulb, primarily within the granule cell layer and external plexiform layer. The question arises, therefore, as to why the effects of olfactory conditioning are limited to focal, odor-specific regions of the bulb, as defined by spatial patterns of focal 2-DG uptake (Sullivan and Leon, 1986; Wilson and Leon, 1988a). The odor-specific spatial pat-
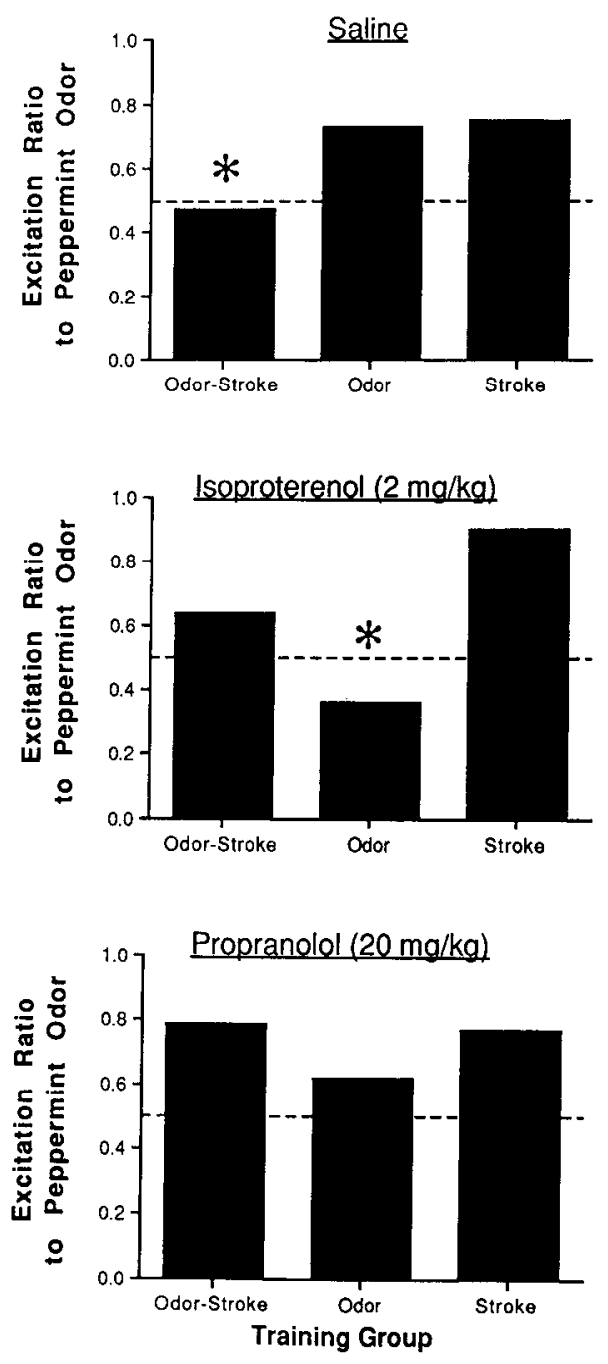

Figure 5. Mitral/tufted cell excitation ratios (\% excited/total \% responsive) to the CS odor. Pups had previously been trained in either the Odor-Stroke, Odor only, or Stroke only conditioning groups, and received an injection of either saline, isoproterenol, or propranolol. An excitation ratio of less than 0.5 signified that, of the cells that responded to the odor, more were suppressed than excited. Only Odor-StrokeSaline and Odor only-Isoproterenol demonstrated this modified response pattern to the learned odor.

terns of glomerular layer 2-DG uptake (which occur even in untrained animals) are believed to be at least partially due to the spatial distributions of odor sensitivity across the olfactory epithelium (Thommesen and Doving, 1977; MacKay-Sim et al., 1982). This spatial pattern of receptor sensitivity is mapped onto the olfactory bulb by the loose topographic projection of the olfactory nerve to the bulb (LeGros Clark, 1951; Land, 1973; Costanzo and O'Connell, 1978; Schwob and Gottlieb, 1986; Astic et al., 1987; Stewart and Pedersen, 1987; Gervais et al., 1988). During olfactory conditioning then, localized regions of the bulb receive odor-specific input via the olfactory nerve (CS), while the entire bulb is activated by the nonspecific NE input produced by stroking (UCS) or isoproterenol. Thus, a cooperativity or association between incoming focal olfactory nerve activity and global NE activity during training may be required for induction of the neural plasticity underlying early olfactory memories (Leonard, 1981; Gervais et al., 1988).

A similar series of events has been described for neural plas- 
ticity in the developing cat visual cortex. The plasticity in visual cortical neurons induced by early monocular deprivation, for example, is dependent on the presence of NE and perhaps other neuromodulators/neurotransmitters (Kasamatsu and Pettigrew, 1979; Bear and Singer, 1986; Gordon et al., 1988). Thus, the pairing of primary visual input with increased NE activity is required for plasticity to occur in the visual cortex.

\section{Biological significance}

It is likely that the type of neurobehavioral phenomena associated with learning described here actually occur during normal contact between the dam and littermates. The conditioning paradigm used in the present experiments is naturalistic; no restrictions or deprivations are placed on the pup. Pups are simply taken from the dam for a maximum of $30 \mathrm{~min}$ a day for training and returned to the dam. Furthermore, the stimulus paired with the odor to induce the neurobehavioral changes, i.e., tactile stimulation, mimics the stimulation the pup normally receives from the dam. In fact, preliminary evidence from our laboratory suggests that the olfactory bulb exhibits enhanced focal 2-DG uptake when the pup is presented with the dam's natural odor (R. M. Sullivan, D. A. Wilson, A. Correa, R. Wong, and M. Leon, unpublished observations), an odor to which pups normally acquire a preference (Leon, 1974; Brunjes and Alberts, 1979; Galef and Kaner, 1980; Alberts and May, 1984).

The survival of the altricial newborn rat pup is dependent on the pup's ability to identify and locate its mother, which it does through learned olfactory cues. Because of the critical importance of early olfactory learning, the newborn may have a biological predisposition to learn about significant odors in its environment (Garcia and Koeiling, 1966; Rescorla, 1988) in a rapid, reliable manner. Infant rat learning studies suggest that this learning may be so reliable, in part, because many different stimuli are capable of functioning as a reinforcer during this developmental stage. These positively reinforcing stimuli, which have the common feature of arousing pups (Sullivan et al., 1986a, b), appear to be frequently encountered by pups within the nest; e.g., stroking (Pedersen et al., 1982; Sullivan et al., 1986a, b), milk (Thoman et al., 1968; Johanson and Teicher, 1980; Brake, 1981; Johanson and Hall, 1982; Johanson et al., 1984; Sullivan and Hall, 1988), warmth (Guenaire et al., 1982; Alberts and May, 1984), suckling (Amsel et al., 1976; Kenny et al., 1979), maternal odors, and tailpinch (Sullivan et al., 1986a).

The present results, coupled with other recent findings, provide a putative neural substrate for this apparent predisposition; namely, the immaturity of both the olfactory bulb and the noradrenergic locus coeruleus system at birth. During the early postnatal period in the rat, locus coeruleus neurons are electrotonically coupled (Christie et al., 1987). This coupling is high at birth and decreases after day 10 . Electrotonic coupling could increase the sensitivity of responsivity of the locus coeruleus to stimulation by increasing the number of neurons activated by a given sensory input. In fact, in anesthetized neonatal rats, locus coeruleus neurons respond equally well to noxious and non-noxious somatosensory stimuli; as the animal matures, nonnoxious stimuli become less effective at evoking responses ( $\mathrm{Na}$ kamura et al., 1987). A newborn pup receives somatosensory stimulation almost entirely from its mother and littermates, and this stimulation ranges from being licked and groomed (presumably non-noxious) to being stepped on and bitten (presumably noxious). Thus, the probability of maternal odor being paired with locus coeruleus activity is greatly increased during early postnatal life, and as demonstrated here, this pairing may be necessary for learning odor preferences. The combined action of odor stimulation and locus coeruleus activity during early postnatal life may influence olfactory bulb development to differentially encode odors experienced at that time.

\section{References}

Alberts, J. R., and B. May (1984) Nonnutritive, thermotactile induction of filial huddling in rat pups. Dev. Psychobiol. 17: 161-181.

Amsel, A., D. R. Burdette, and R. Letz (1976) Appetitive learning, patterned alteration and extinction in 10-day-old rats with non-lactating suckling as reward. Nature 262: 816-818.

Astic, L., and D. Saucier (1982) Ontogenesis of the functional activity of rat olfactory bulb: Autoradiographic study with the 2-deoxyglucose method. Dev. Brain Res. 2: 243-256.

Astic, L., and D. Saucier (1986) Anatomical mapping of the neuroepithelial projection to the olfactory bulb in the rat. Brain Res. Bull. 16: $445-454$

Astic, L., D. Saucicr, and A. Hollcy (1987) Topographical rclationships between olfactory receptor cells and glomerular foci in the rat olfactory bulb. Brain Res. 424: 144-152.

Barnett, S. A., and D. Z. Walker (1974) Early stimulation, parental behavior, and the temperature of infant mice. Dev. Psychobiol. 7: 563-577.

Bear, M. F., and W. Singer (1986) Modulation of visual cortical plasticity by acetylcholine and noradrenaline. Nature 320: 172-176.

Brake, S. C. (1981) Suckling infant rats learn a preference for a novel olfactory stimulus paired with milk delivery. Science 211: 506-508.

Brunjes, P. C., and J. R. Alberts (1979) Olfactory stimulation induces filial huddling preferences in pups. J. Comp. Psychol. 93: 548-555.

Brunjes, P. C., L. K. Smith-Crafts, and R. McCarty (1985) Unilateral odor deprivation: Effects on the development of olfactory bulb catecholamines and behavior. Dev. Brain Res. 22: 1-6.

Caza, P. C. (1984) Noradrenergic influences on blocking: Interactions with development. Physiol. Behav. 21: 9-17.

Christie, M. J., J. T. Williams, and R. A. North (1987) Synchronous activity in locus coeruleus neurons from neonatal rats. Soc. Neurosci. Abstr. 13: 538.

Coopersmith, R., and M. Leon (1984) Enhanced neural response to familiar olfactory cues. Science 225: 849-851.

Coopersmith, R., and M. Leon (1986) Enhanced neural response by adult rats to odors experienced early in life. Brain Res. 371:400-403.

Coopersmith, R., S. Henderson, and M. Leon (1986) Odor specificity of the enhanced neural response following odor experience in rats. Dev. Brain Res. 27: 191-197.

Cornwell-Jones, C. A., and H. R. Bollers (1983) Neonatal 6-hydroxydopamine alters conspecific odor investigation by male rats. Brain Res. 268: 291-294.

Costanzo, R. M., and R. J. O'Connell (1978) Spatially organized projections of hamster olfactory nerves. Brain Res. 139: 327-332.

Do, J., R. M. Sullivan, and M. Leon (1988) Behavioral and neural correlates of postnatal olfactory conditioning: II. Respiration during conditioning. Dev. Psychobiol. 21: 591-600.

Doty, R. L., M. Ferguson-Segall, I. Lucki, and M. Kreider (1988) Effects of intrabulbar injections of 6-hydroxydopamine on ethyl acetate odor detection in castrate and no-castrate male rats. Brain Res. 444: 95-103.

Evoniuk, G. E., C. M. Kuhn, and S. M. Schanberg (1978) The effect of tactile stimulation on serum growth hormone and tissue ornithine decarboxylase in rat pups. Comm. Psychopharm. 3: 363-370.

Galef, B. G., Jr., and H. C. Kaner (1980) Establishment and maintenance of preference for natural and artificial olfactory stimuli in juvenile rats. J. Comp. Physiol. Psychol. 94: 588-595.

Gallistel, C. R., C. Piner, T. O. Allen, N. T. Adler, E. Yadin, and M. Negin (1982) Computer assisted analysis of 2-DG autoradiography. Neurosci. Biobehav. Rev. 6: 409-420.

Garcia, J., and R. A. Koelling (1966) Relation of cue to consequence in avoidance learning. Psychon. Sci. 4: 123-124.

Gervais, R., and J. Pager (1983) Olfactory bulb excitability selectively modified in behaving rats after local 6-hydroxydopamine treatment. Behav. Brain Res. 9: 165-179.

Gervais, R., A. Holley, and B. Keverne (1988) The importance of central noradrenergic influences on the olfactory bulb in the processing of learned olfactory cues. Chem. Senses 13: 3-12. 
Goodman, L. S., and A. G. Gilman (1985) The Pharmacological Basis of Therapeutics, Macmillan, New York.

Gordon, B., E. E. Allen, and P. Q. Trombley (1988) The role of norepinephrine in plasticity of visual cortex. Prog. Neurobiol. 30: 171191.

Gray, C. M., W. J. Freeman, and J. E. Skinner (1986) Chemical dependencies of learning in the rabbit olfactory bulb: Acquisition of the transient spatial pattern depends on norepinephrine. Behav. Neurosci. 100; 585-596.

Greer, C. A., W. B. Stewart, J. S. Kauer, and G. M. Shepherd (1981) Topographical and laminar localization of 2-deoxyglucose uptake in rat olfactory bulb induced by electrical stimulation of olfactory nerves. Brain Res. 217: 279-293.

Guenaire, C., J. C. Costa, and J. Delacour (1982) Discrimination spatiale avec renforcement thermique chez jeune rat. Physiol. Behav. 28: 725-731.

Hall, W. G. (1979) Feeding and behavioral activation in infant rats. Science 205: 206-209.

Hofer, M. A. (1987) Shaping forces within early social relationships. In Perinatal Development, N. A. Krasnegor, E. M. Blass, M. A. Hofer, and W. P. Smotherman, eds., pp. 251-274, Academic, New York.

Jahr, C. E., and R. A. Nicoll (1982) Noradrenergic modulation of dendrodendritic inhibition in the olfactory bulb. Nature 297: 227229.

Jastreboff, P. J., P. E. Pedersen, C. A. Greer, W. B. Stewart, J. S. Kauer, T. E. Benson, and G. M. Shepherd (1984) Specific olfactory receptor populations projecting to identified glomeruli in the rat olfactory bulb. Proc. Natl. Acad. Sci. USA 81: 5250-5254.

Johanson, I. B., and W. G. Hall (1982) Appetitive conditioning in neonatal rats: Conditioned orientation to a novel odor. Dev. Psychobiol. 15: 379-397.

Johanson, I. B., and M. Teicher (1980) Classical conditioning of an odor preference in 3-day-old rats. Behav. Neural Biol. 29: 132-136.

Johanson, I. B., J. M. Polefrone, and W. G. Hall (1984) Appetitive conditioning in neonatal rats: Conditioned ingestive responding to stimuli paired with oral infusions of milk. Dev. Psychobiol. 17: 357381 .

Jourdan, R., A. Duveau, L. Astic, and A. Holley (1980) Spatial distribution of [14C]-2-deoxyglucose uptake in the olfactory bulbs of rats stimulated with two different odours. Brain Res. 188: 139-154.

Kasamatsu, T., and J. D. Pettigrew (1979) Preservation of binocularity after monocular deprivation in the striate cortex of kittens treated with 6 hydroxydopamine. J. Comp. Neurol. 185: 139-162.

Kelly, P. A. T., and T. McCullough (1981) Errors associated with modifications of quantitative 2-deoxyglucose technique. J. Cereb. Blood Flow Met. (Suppl.) 1: 60-61.

Kenny, J. T., M. L. Stoloff, J. P. Bruno, and E. M. Blass (1979) Ontogeny of preference for nutritive over nonnutritive suckling in albino rats. J. Comp. Physiol. Psychol. 93: 752-759.

Keverne, E. B., and C. de la Riva (1982) Pheromones in mice: Reciprocal interaction between the nose and the brain. Nature 296: 148150.

Kuhn, C. M., S. R. Butler, and S. M. Schanberg (1978) Selective depression of serum growth hormone during maternal deprivation in rat pups. Science 201: 1034-1036.

Land, L. J. (1973) Localized projection of the olfactory nerves to rabbit olfactory bulb. Brain Res. 63: 153-166.

LeGros Clark, W. E. (1951) The projection of the olfactory epithelium on the olfactory bulb in the rabbit. J. Neurol. Neurosurg. Psychiatry 14: $1-10$.

Leon, M. (1974) Maternal pheromone. Physiol. Behav. 13: 441-453.

Leon, M., B. G. Galef, and J. Behse (1977) Establishment of pheromonal bonds and diet choice in young rats by odor pre-exposure. Physiol. Behav. 18: 387-391.

Leonard, C. (1981) Some speculations concerning neurological mechanisms for early olfactory recognition. In Development of Perception Psychobiological Perspectives, Vol. 1, R. W. Aslin, J. R. Alberts, and M. R. Pedersen, eds., pp. 383-410, Academic, New York.

MacKay-Sim, A., P. Shaman, and D. G. Moulton (1982) Topographic coding of olfactory quality: Odorant-specific patterns of epithelial responsivity in the salamander. J. Neurophysiol. 48: 584-596.

Martinez, J. L., Jr. (1986) Memory: Drugs and hormones. In Learning and Memory: A Biological View, J. L. Martinez, Jr., and R. P. Kessner eds., pp. 127-164, Academic Press, New York.

McGaugh, J. L. (1983) Hormonal influence on memory. Annu. Rev. Psychol. 34: 297-323.
McLean, J. H., and M. T. Shipley (1987) Postnatal development of noradrenergic afferents to the olfactory bulb. Assoc. Chemorecept. Sci. Abstr. 169.

Mirkin, B. I. (1970) Developmental pharmacology. Annu. Rev. Pharmacol. 10: 255-272.

Morasco, E. M., C. A. Cornwell-Jones, and S. Sobrian (1979) 6-Hydroxydopamine reduces preference for conspecific but not other familiar odors in rat pups. Pharmacol. Biochem. Behav. 10: 319-323.

Nakamura, S., F. Kimura, and T. Sakaguchi (1987) Postnatal development of electrical activity in the locus coeruleus. J. Neurophysiol. 58: 510-524.

Pedersen, P. E., C. L. Williams, and E. M. Blass (1982) Activation and odor conditioning of suckling behavior in 3-day-old albino rats. J. Exp. Psychol.: Anim. Behav. Proc. 8: 329-341.

Perez, H., A. Hernandez, and C. R. Almli (1987) Locus coeruleus stimulation modulates olfactory bulb evoked potentials. Brain Res. Bull. 18: 767-770.

Pissonnier, D., J. C. Thiery, C. Fabre-Nys, P. Poindron, and E. B. Keverne (1985) The importance of olfactory bulb noradrenaline for maternal recognition in sheep. Physiol. Behav. 35: 361-363.

Rescorla, R. A. (1988) Behavioral studies of Pavlovian conditioning. Annu. Rev. Neurosci. 11: 329-352.

Rosser, A. E., and E. B. Keverne (1985) The importance of central noradrenergic neurones in the formation of an olfactory memory in the prevention of pregnancy block. Neuroscience 15: 1141-1148.

Royet, J. P., R. Gervais, and S. Arenda (1983) Effect of local 6-OHDA and 5,6-DHT injections into the rat olfactory bulb on neophobia and learned aversion to a novel food. Behav. Brain Res. 10:297-309.

Schwob, J. E., and D. I. Gottlieb (1986) The primary olfactory projection has two chemically distinct zones. J. Neurosci. 6: 3393-3404.

Sharp, F., J. Kauer, and G. M. Shepherd (1975) Local sites of activity related glucose metabolism in rat olfactory bulb during olfactory stimulation. Brain Res. 263: 97-103.

Sharp, F. R., T. S. Kilduff, S. Bzorgchami, H. Heller, and A. F. Ryan (1983) The relationship of local cerebral glucose utilization to optical density ratios. Brain Res. 263: 97-103.

Shipley, M. T., F. J. Halloran, and J. De la Torre (1985) Surprisingly rich projection from locus coeruleus to the olfactory bulb in the rat. Brain Res. 329: 294-299.

Stewart, W. B., and P. E. Pedersen (1987) The spatial organization of the olfactory nerve projections. Brain Res. 411: 248-258.

Stewart, W. B., J. S. Kauer, and G. M. Shepherd (1979) Functional organization of rat olfactory bulb analyzed by the 2-deoxyglucose method. J. Comp. Neurol. 185: 715-734.

Sullivan, R. M., and W. G. Hall (1988) Reinforcers in infancy: Classical conditioning using stroking or intra-oral infusions of milk as a UCS. Dev. Psychobiol. 21: 215-223.

Sullivan, R. M., and M. Leon (1986) Early olfactory learning induces an enhanced olfactory bulb response in young rats. Dev. Brain Res. 27: 278-282.

Sullivan, R. M., and M. Leon (1987) One-trial olfactory learning enhances olfactory bulb responses to an appetitive conditioned odor in 7-day-old rats. Dev. Brain Res. 35: 301-311.

Sullivan, R. M., S. C. Brake, M. A. Hofer and C. L. Williams (1986a) Huddling and independent feeding of neonatal rats is enhanced by a conditioned change in behavioral state. Dev. Psychobiol. 19: 625635.

Sullivan, R. M., M. A. Hofer, and S. C. Brake (1986b) Olfactoryguided orientation in neonatal rats is enhanced by a conditioned change in behavioral state. Dev. Psychobiol. 19:615-623.

Sullivan, R. M., D. A. Wilson, M. H. Kim, and M. Leon (1988) Behavioral and neural correlates of postnatal olfactory conditioning: I. Effects of respiration on conditioned neural responses. Physiol. Behav. 44: 85-90.

Sullivan, R. M., D. A. Wilson, and M. Leon (1989) Associative processes in early olfactory preference acquisition: Neural and behavioral consequences. Psychobiology 17: 29-33.

Thoman, E., A. Wetzel, and S. Levin (1968) Learning in the neonatal rat. Anim. Behav. 16: 54-57.

Thommesen, G., and K. B. Doving (1977) Spatial distribution of the EOG in the rat: A variation with odor quality. Acta Physiol. Scand. 99: $270-280$.

Wilson, D. A., and M. Leon (1988a) Spatial patterns of olfactory bulb single-unit responses to learned olfactory cues in young rats. J. Neurophysiol. 59: 1770-1782.

Wilson, D. A., and M. Leon (1988b) Noradrenergic modulation of 
olfactory bulb excitability in the postnatal rat. Dev. Brain Res. 42: 69-75.

Wilson, D. A., R. M. Sullivan, and M. Leon (1985) Odor familiarity alters mitral cell response in the olfactory bulb of neonatal rats. Dev. Brain Res. 22: 314-317.

Wilson, D. A., R. M. Sullivan, and M. Leon (1987) Single-unit analysis of postnatal olfactory learning: Modified olfactory bulb output response patterns of learned attractive odors. J. Neurosci. 7: 31543162 .
Woo, C. C., and M. Leon (1988) Sensitive period for neural and behavioral response development to learned odors. Dev. Brain Res. 36: 309-313.

Woo, C. C., R. Coopersmith, and M. Leon (1987) Localized changes in olfactory bulb morphology associated with early olfactory learning. J. Comp. Neurol. 236: 113-125. 